\title{
Study of the Demand for Urgent Treatment in General Practice
}

\author{
J. A. FORBES,* M.A., M.D. ; L. M. M. MUTCH,* M.в., CH.B. ; G. T. SMITH,* M.A., B.M., в.CH. ; \\ A. J. TULLOCH,* M.B., CH.B., D.OBST.R.C.O.G.
}

Brit. med. F., 1967, 3, 856-858

The service that general practitioners give to their patients is based largely on the demands as opposed to the needs of their patients. As a result a disproportionate amount of time may be spent on the trivial and self-limiting, to the detriment of those patients who suffer from serious conditions.

The distribution of disease in general practice has been extensively investigated (College of General Practitioners, 1962, 1965). A more specific approach has been made by Backett et al. (1954), Brotherston et al. (1959), and Fry and Dillane (1964) by estimating the severity of conditions met with in general practice.

In this study we have looked at the subject from a different viewpoint. An appointment system has been used in this practice for six years. It has proved workable, and acceptable to the majority of patients, but one of the difficulties of such a system is that it needs to be flexible enough to accommodate those patients who come requesting treatment at short notice. If demands of this type are excessive the amount of time which the general practitioner can allot to the supervision of patients suffering from chronic conditions is reduced.

This investigation was initiated to study the nature and extent of this element of urgent demand so that plans could be made to ensure that those patients with serious chronic disease receive the time and care to which they are entitled.

\section{Method}

This practice is based on a small market town of some 8,000 inhabitants: $55 \%$ of our patients live in the town, and $45 \%$ in the surrounding countryside. The survey was confined to surgery attendances. Requests for home visits, antenatal attendances, and attendances at infant welfare clinics were excluded.

Urgent demand was defined as follows: when a patient made contact with the practice and stated that his condition was such that he required medical advice on the same day, he was regarded as having made an urgent demand. The onus for deciding whether treatment was necessary rested with the patient. When such a patient attended the surgery the first part of a form consisting mainly of identification data was completed by the clerical staff. The second part of the form, which included the diagnosis, the reason for the patient's attendance, and the time taken for consultation, was completed by the doctor who treated the patient. The information recorded on the form was coded and transferred to punchcards. The analyses were carried out by means of business machines under the aegis of the Oxford Record Linkage Study. Information about the age and sex structure of the practice and its geographical distribution during the survey was derived

* General Practitioners, Bicester, Oxfordshire. by means of a system of data retrieval described elsewhere (Acheson and Forbes, 1967).

\section{Results}

The number of patients at risk midway through the study was 6,850 . About one in four who attended the surgery during the nine-week period thought that treatment was necessary the same day (Table I). It would seem, therefore, that about $25 \%$ of all surgery appointments should be allotted to patients requiring urgent treatment. It will be seen from Table II, however, that the daily distribution is uneven, suggesting that the number of appointments reserved for urgent cases should vary according to the day of the week. TABLE I.-Proportion of Urgent Attendances Demand Compared with

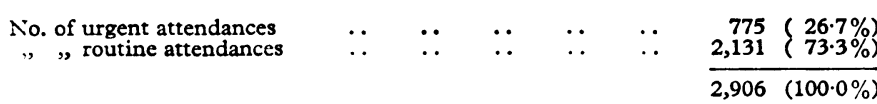

TABLE II.-Proportions of Urgent Demand Attendances by Week-day

No. of Attendances

Monday

Tuesday

Whursday ...

Friday $\quad:$.

$\because$
$\because$
$\because$
$\because$

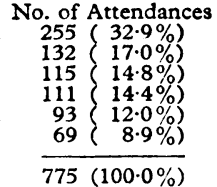

Attendance rates by age and sex were computed from the age and sex distribution of the total practice (Table III). Preschool children made greater demands in relation to their numbers in the practice than the other groups. The middleaged and elderly made fewer demands relative to their numbers, and attendance rates in young pre-school boys was almost four times that in elderly men.

The practice is divided into five zones-central, north, south, east, and west. The central zone is the town in which the practice premises are situated, and the surrounding country-

\begin{tabular}{|c|c|c|c|c|}
\hline \multirow[b]{2}{*}{ Age Group } & \multicolumn{2}{|c|}{ Males } & \multicolumn{2}{|c|}{ Females } \\
\hline & $\begin{array}{c}\text { No. of } \\
\text { Attendances }\end{array}$ & $\begin{array}{l}\text { Attendance } \\
\text { Rate } / 1,000\end{array}$ & $\begin{array}{c}\text { No. of } \\
\text { Attendances }\end{array}$ & $\begin{array}{l}\text { Attendance } \\
\text { Rate } / 1,000\end{array}$ \\
\hline $\begin{array}{ll}\text { Pre-school }(0-4 \text { yrs }) & \ldots \\
\text { School }(5-14 \text { yrs }) & \ldots \\
\text { Young aduits }(15-44 \text { yrs) } \\
\text { Middle-aged }(45-64 \text { yrs) } \\
\text { Elderly }(65+\text { yrs })\end{array}$ & $\begin{array}{r}91 \\
65 \\
139 \\
71 \\
12\end{array}$ & $\begin{array}{r}208 \\
111 \\
119 \\
77 \\
53\end{array}$ & $\begin{array}{r}68 \\
72 \\
183 \\
63 \\
11\end{array}$ & $\begin{array}{r}153 \\
131 \\
118 \\
99 \\
48\end{array}$ \\
\hline Total & 378 & & 397 & \\
\hline
\end{tabular}


side, containing a number of villages, is divided into quadrants. From our knowledge of the number of patients in each zone it was possible to compute attendance rates for each zone during the study (Table IV). We had anticipated that the patient's decision to attend surgery for urgent consultation might be influenced by the distance he lived from the surgery, but this did not appear to be generally true ; for example, in the north zone the female attendance rate exceeded that in all other zones.

TABLE IV.-Attendance Rates for Urgent Treatment by Zone

\begin{tabular}{|c|c|c|c|c|c|c|}
\hline & & & \multicolumn{2}{|c|}{ Males } & \multicolumn{2}{|c|}{ Females } \\
\hline \multicolumn{3}{|c|}{ Zone } & $\begin{array}{c}\text { No. of } \\
\text { Attendances }\end{array}$ & $\begin{array}{l}\text { Attendance } \\
\text { Rate/1,000 }\end{array}$ & $\begin{array}{c}\text { No. of } \\
\text { Attendances }\end{array}$ & $\begin{array}{l}\text { Attendance } \\
\text { Rate } / 1,000\end{array}$ \\
\hline $\begin{array}{l}\text { Central.. } \\
\text { North } \\
\text { South } \\
\text { East } \\
\text { West }\end{array}$ & $\begin{array}{l}\because \\
\cdots \\
\cdots\end{array}$ & $\begin{array}{l}\because \\
\because \\
\therefore\end{array}$ & $\begin{array}{r}237 \\
33 \\
50 \\
34 \\
24\end{array}$ & $\begin{array}{r}121 \\
125 \\
81 \\
123 \\
98\end{array}$ & $\begin{array}{r}231 \\
64 \\
48 \\
21 \\
33\end{array}$ & $\begin{array}{r}117 \\
171 \\
105 \\
77 \\
116\end{array}$ \\
\hline Total & . & . & 378 & & 397 & \\
\hline
\end{tabular}

A classification of the cases in terms of diagnoses made is shown in Table V. During the study a distinction was made between upper respiratory tract infections ; cardiac and respiratory conditions ; conditions of the ear, nose, and throat ; and eye infections; it was found, however, that the vast majority of these patients were suffering from acute infections of the upper respiratory tract. In Table V, therefore, all these conditions are grouped under " upper respiratory tract infection." Similarly, a distinction was made between trauma and skeletal conditions-for example, low back pain-but the distinction of ten proved difficult to make, and consequently all those in these two groups have been classified under the heading of trauma. About $65 \%$ of all patients attending for urgent treatment were suffering from upper respiratory tract infections or trauma, a fact which has important implications should a trained nurse be employed. With some experience and judgement it should be possible for her to treat, or at least temporarily reassure, a large proportion of the patients in this group.

TABLB V.-Classification of Cases by Diagnosis

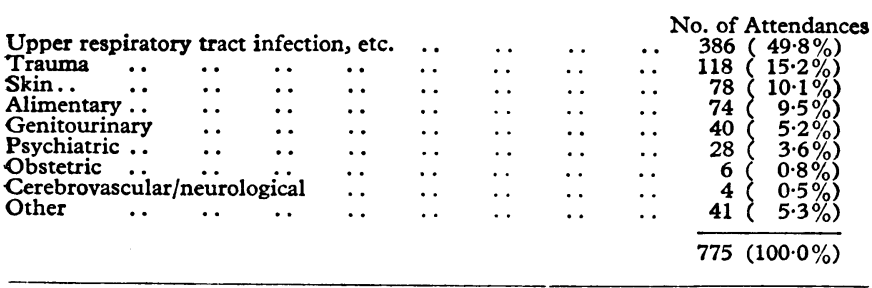

An attempt was made during the study to determine why each patient had decided that treatment was required urgently. It seemed to us that the majority of patients could be placed in one of the following categories: (1) the patient was suffering from a condition which merited urgent treatment; (2) the patient was suffering from a condition which could not be regarded as urgent, and his primary reason for attendance was to seek reassurance; and (3) the patient was inconsiderate or frivolous.

We were aware that the placing of patients in one of these categories was arbitrary, and subject to observer variation. What may appear to an overworked doctor to be inconsiderate or frivolous behaviour on the part of a patient may not appear as such to the patient, or indeed to another doctor. In the same way a man of 55 with chest pain of sudden onset is suffering from a condition meriting urgent consultation, but at the same time he is also seeking reassurance. Despite the disadvantages, we felt that an attempt to explore, even superficially, the motivation for seeking urgent medical advice was justified, and the question was included in the study, with the proviso that any results should be treated with reserve (Table VI).
TABLE VI.-Reason for Seeking Medical Advice in Total Number of Patients Attending for Urgent Treatment

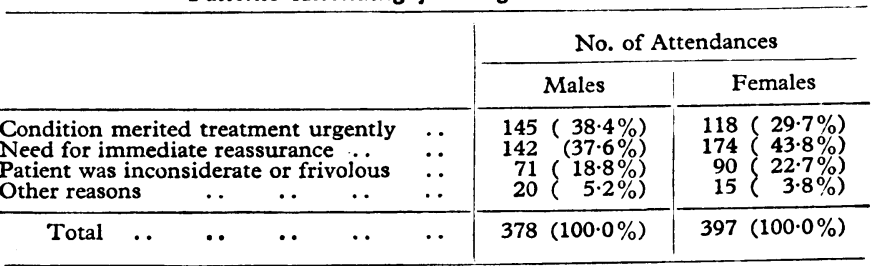

During the study it became clear that a number of patients had made more than one demand for urgent treatment during the nine-week period, and this was confirmed when the results were analysed. Eighty-six patients (47 males and 39 females) were responsible for 190 items of urgent demand, constituting $24.5 \%$ of all urgent attendances. Our results also showed that 146 family units* created 362 items of urgent demand-that is, $47 \%$ of all urgent demand. To put it another way, the representatives of 146 families, composed of some 500 persons (approximately $7 \%$ of the total practice) were responsible for almost half of all the demands for urgent treatment during the survey period.

\section{Discussion}

Though the immediate aim of this study has been to examine the nature and extent of urgent demand for medical advice and treatment, the long-term objective is to organize our work in such a way that more time is spent where it is most needed. We hold the view that patients who present with an acute illness, whether trivial or serious, are already receiving a firstclass service, but that our supervision of those suffering from chronic conditions is of indifferent quality. Our problem, therefore, is to maintain the standard of service given to the acutely ill, and at the same time, with our limited resources, to improve the standard of care given to those suffering from chronic disease.

In an attempt to achieve these long-term objectives we propose taking the following measures.

(1) There appears to be no reason why a trained nurse should not filter a large proportion of urgent demand cases. It has been shown that urgent demand constitutes $25 \%$ of surgery attendances, so that if a nurse could advise or treat even half of those patients a considerable saving of doctors' time would be effected.

(2) We propose identifying those patients who feel the need for repeated attendances at a doctor's surgery. Clearly, they need support, advice, and education in the use of the generalpractitioner services. With the help of the district nurse, the health visitor, and, if possible, a medical social worker we hope to be able to do this and relieve some of the pressure on the general practitioner. We suggest that a full-scale medical and social investigation of these families would yield valuable information.

(3) During the past few months a chronic disease register has been compiled, consisting of those patients who require regular supervision. It is proposed that these patients should no longer be seen during surgery hours but at special clinics, when more time can be spent with each patient. This will also have the effect of reducing the numbers attending during regular surgery hours.

\section{Summary}

Our investigation into the nature and extent of urgent demand in a general practice during a nine-week period showed that $25 \%$ of surgery attendances were urgent, the heaviest demand being made early in the week. Attendance rates were

* A family unit was definet as a husband and/or wife and/or children living at the same address. 
highest in young children. Two out of three patients were suffering from infection of the upper respiratory tract or trauma. It appeared that the distance the patient lived from the surgery played little part in his decision to seek medical advice urgently.

Eighty-six patients were responsible for about a quarter of all attendances, and 146 families for almost half of all urgent demands.

The measures proposed to be taken on the basis of these results are outlined.

We wish to record our thanks to Dr. E. D. Acheson, Director of the Oxford Record Linkage Study, for his helpful advice.
The practice described is associated with the Oxford Record Linkage Study, and one of us (J.A. F.) is in receipt of financial support from the funds allocated by the Nuffield Provincial Hospital Trust to that Study.

\section{REFERENCES}

Acheson, E. D., and Forbes, J. A. (1967). To be published.

Backett, E. M., Heady, J. A., and Evans, J. C. G. (1954). Brit. med. 7., $1,109$.

Brotherston, J. H. F., Cartwright, Ann, Cowan, J. L. Baldwin, J. T., Douglas, E. C. K., and Steele, G. A. (1959). Ibid., 2, 1169.

College of General Practitioners (1962). Studies on Medical and Popu-

lation Subjects, No. 14, p. 2. H.M.S.O., London.
(1965). Report on Present State and Future Needs. London.

Fry, J., and Dillane, J. B. (1964). Lancet, 2, 632.

\section{HOSPITAL TOPICS}

\section{Neasden Memorandum on Resuscitation}

On 16 May 1966 a memorandum on the condition of the patient which may occur resuscitation after respiratory failure and for a variety of possible reasons in the course cardiac arrest was issued by the physician of an illness and action to remedy 'cardiac superintendent of Neasden Hospital to all arrest' which sometimes occurs in a patient medical officers and senior nursing staff. This stated that

"The following patients are not to be resuscitated:

Very elderly, over 65 years.

Malignant disease.

Chronic chest disease.

Chronic renal disease.

Top of yellow treatment card to be marked N.T.B.R. (i.e., not to be resuscitated).

The following people should be resuscitated:

Collapse as a result of diagnostic or therapeutic procedure-e.g., needle in pleura (even if over 65 years).

Sudden unexpected collapse under 65 years-i.e., loss of consciousness, cessation of breathing, no carotid pulsation."

The existence of this memorandum was disclosed in the B.B.C. television programme Tomorrow's World, which was shown on 20 September. Subsequently it was discussed extensively both on television and in the national press.

\section{Committee of Inquiry}

On 22 September a statement was made by a committee set up by the North-west Metropolitan Regional Hospital Board to inquire into the circumstances in which the notice was issued. The members of this committee comprised Miss E. RICHARDS, F.R.C.S. (vice-chairman of the board), Sir Charles Harington, F.R.S. (member of the board), assisted by Dr. F. J. Fowler and Mr. G. H. Weston, respectively senior administrative medical officer and secretary of the board. The statement reads as follows:

"In considering the problem it is important to differentiate between emergency action to combat collapse or a sudden worsening in whose life is already in grave jeopardy due to occur in the course of an illness from which recovery is possible. It should be understood that a patient whose heart stops beating dies unless cardiac action can be started again within at most three minutes, and that the instructions issued were concerned with attempts which must be made within seconds to restore life before the condition becomes irreversible and the patient dies. Action to remedy cardiac arrest can only be appropriately taken in certain cases and each individual case must be a medical decision.

"The Board is assured that no patient who might have benefited by resuscitative treatment during the currency of the notice failed to receive it.

"On the authority of the Vice-chairman of the Board (in the absence of the Chairman abroad) the Board has accepted the report and is acting upon its recommendations. A copy has been sent to the Minister of Health, who has informed the Board that he also accepts the report.

"The findings of fact of members of the Committee of Enquiry are as follows:

" (1) That the idea of issuing instructions on the selection of patients for resuscitation arose from responsible discussion by medical staff in the Central Middlesex Hospital Management Committee Group and their decision that guidance to medical staff and in practice to nursing staff was necessary in the light of experience of wrong use of the resources available.

“(2) That it was also agreed that medical staff in clinical charge of patients should mark case papers of patients who should not be resuscitated.

"(3) That Dr. McMath, the physician superintendent, after seeing a film and hearing a talk on resuscitation given to the staff at Neasden Hospital, prepared the memorandum dated 16 May 1966 and circulated it within the hospital.
“(4) That the Hospital Management Committee and the administrative staff were not involved in the decision to issue such a memorandum, in the composition of the memorandum, nor in the means of disseminating it."

The conclusions of the members of the of the evidence they elicited are as follows:

“(a) That some guidance to medical staff on selection of patients is necessary to the proper use of resources and for the protection of some patients from distressing and unprefitable procedures.

" (b) That age is one of the factors on which the decision on an individual patient may properly be taken, but that any guidance given should in no way imply that a patient should be excluded from consideration for resuscitation merely by reason of age or diagnostic classification.

" (c) That the decision on each patient should be taken at the highest medical level available in the particular circumstances and should not be left to nursing staff.

" (d) That if it is found necessary to mark case papers to denote whether a patient is considered a suitable subject for resuscitation, the guidance relating to the interpretation of any marking symbol adopted should not be displayed but should be communicated in confidence to staff who need to be aware of it.

" (e) That guidance issued relating to the procedure to be adopted by nursing staff for summoning the resuscitation team in cases of cardiac arrest should be given separately from guidance given regarding interpretation of the marking system.

“ $(f)$ That although Dr. McMath's initiative in attempting to formulate guidance for medical staff on the selection of patients for resuscitation is in itself to be commended we regard the wording of the memorandum issued over his signature as particularly unfortunate and we greatly deplore its distribution in a way which rendered it liable to public view, in which position it remained unchallenged over a considerable period.

" (g) That we support the action taken by the Senior Administrative Medical Officer on 